\title{
Cilastatin Attenuates Cisplatin-Induced Proximal Tubular Cell Damage
}

\author{
Sonia Camano, Alberto Lazaro, Estefania Moreno-Gordaliza, Ana M. Torres, \\ Carmen de Lucas, Blanca Humanes, Jose A. Lazaro, M. Milagros Gomez-Gomez, \\ Lisardo Bosca, and Alberto Tejedor
}

Renal Physiopathology Laboratory, Department of Nephrology, Hospital General Universitario Gregorio Marañón, Madrid, Spain (S.C., A.L., A.M.T., C.d.L., B.H., J.A.L., A.T.); Department of Analytical Chemistry, Faculty of Chemistry, Universidad Complutense, Madrid, Spain (E.M.-G., M.M.G.-G.); and Instituto de Investigaciones Biomedicas Alberto Sols (CSIC-UAM), Madrid, Spain (L.B.)

Received January 8, 2010; accepted April 29, 2010

\begin{abstract}
A major area in cancer therapy is the search for protective strategies against cisplatin-induced nephrotoxicity. We investigated the protective effect of cilastatin on cisplatininduced injury to renal proximal tubular cells. Cilastatin is a specific inhibitor of renal dehydrodipeptidase I (DHP-I), which prevents hydrolysis of imipenem and its accumulation in the proximal tubule. Primary cultures of proximal cells were treated with cisplatin $(1-30 \mu \mathrm{M})$ in the presence or absence of cilastatin $(200 \mu \mathrm{g} / \mathrm{ml})$. Apoptosis and mitochondrial injury were assessed by different techniques. Cisplatin uptake and DNA binding were measured by inductively coupled plasma spectrometry. HeLa cells were used to control the effect of cilastatin on the tumoricidal activity of cisplatin. Cisplatin increased cell death, apoptotic-like morphology, caspase activation, and mitochondrial injury in proximal tu-
\end{abstract}

bular cells in a dose- and time-dependent way. Concomitant treatment with cilastatin reduced cisplatin-induced changes. Cilastatin also reduced the DNA-bound platinum but did not modify cisplatin-dependent up-regulation of death receptors (Fas) or ligands (tumor necrosis factor $\alpha$, Fas ligand). In contrast, cilastatin did not show any effects on cisplatintreated HeLa cells. Renal DHP-I was virtually absent in HeLa cells. Cilastatin attenuates cisplatin-induced cell death in proximal tubular cells without reducing the cytotoxic activity of cisplatin in tumor cells. Our findings suggest that the affinity of cilastatin for renal dipeptidase makes this effect specific for proximal tubular cells and may be related to a reduction in intracellular drug accumulation. Therefore, cilastatin administration might represent a novel strategy in the prevention of cisplatin-induced acute renal injury.
Cisplatin (also known as cis-diammine-dichloroplatinum II) is one the most potent antineoplastic drugs used for the treatment of many types of tumors (Boulikas and Vougiouka,

This work was supported in part by the Fondo de Investigaciones Sanitarias [Grants FIS-PI05/2259, FIS-PI08/1481]; Spanish Ministry of Science and Innovation [Grants CTQ2008-04873/BQU, BFU2008-02161]; Comunidad de Madrid [Grant CIFRA 0283/2006]; and Fundacion Mutua Madrilena [Grant TJ2BS]

S.C and A.L. are recipients of a healthcare research contract from Comunidad de Madrid and Fondo de Investigaciones Sanitarias ("Sara Borrell"), respectively

S.C. and A.L. contributed equally to this work.

Article, publication date, and citation information can be found at http://jpet aspetjournals org.

doi:10.1124/jpet.110.165779.
2003). Even though its mechanism of activity has not been clearly established, it is accepted that cisplatin blocks DNA replication and gene transcription by inducing breaks in single- and double-stranded DNA (Servais et al., 2008).

The tumoricidal activity of cisplatin is dose-dependent. In head and neck carcinoma, cisplatin as monotherapy at doses of 100 to $120 \mathrm{mg} / \mathrm{mm}^{2}$ every 3 to 4 weeks has a response rate of 19\% (Liverpool Head and Neck Oncology Group, 1990). At $200 \mathrm{mg} / \mathrm{m}^{2}$, it achieves response rates of $83 \%$ in previously untreated patients (Havlin et al., 1989). Nevertheless, cisplatin has potentially lethal adverse effects. The most common is nephrotoxicity (25-40\% of treated patients), which limits its use and effectiveness in cancer therapy (Yao et al., 2007).

ABBREVIATIONS: RPTECs, renal proximal tubular epithelial cells; OCT, organic cation transporter; DHP-I, dehydrodipeptidase I; DAPI, 4,6diamidino-2-phenylindole; PBS, phosphate-buffered saline; PI, propidium iodide; FITC, fluorescein isothiocyanate; LDH, lactate dehydrogenase; MTT, 3-(4,5-dimethylthiazol-2-yl)-2,5-diphenyltetrazolium; $\Delta \psi \mathrm{m}$, mitochondrial transmembrane potential; CCCP, carbonyl cyanide 3-chlorophenylhydrazone; ICP/MS, inductively coupled plasma/mass spectrometry; SEC, size exclusion; TNF, tumor necrosis factor; Fas-L, Fas ligand; PCR, polymerase chain reaction; RPLPO, ribosomal phosphoprotein large PO subunit; ANOVA, analysis of variance; CFUs, colony-forming units; Pt, platinum; Ir, iridium. 
The glomerular filtration rate can decrease by $30 \%$ after only two doses, and treatments must often be stopped (Go and Adjei, 1999). In fact, only $60 \%$ of patients complete three of four cisplatin cycles.

Cisplatin-induced nephrotoxicity involves enhanced oxidative stress, inflammatory reactions, and tubular cell apoptosis (Lieberthal et al., 1996; Yao et al., 2007; Pabla and Dong, 2008). Several pathways-including extrinsic and intrinsic pathways and the endoplasmic reticulum-are involved in proximal tubular apoptosis (Pabla and Dong, 2008). Several studies have shown that cisplatin directly activates proapoptotic Bcl-2 family proteins such as Bax and Bak in cultured tubular cells and in vivo (Park et al., 2002; Wei et al., 2007), thus leading to mitochondrial permeability transition, release of cytochrome $c$, and activation of caspase 9 , which finally activates caspase 3 , the principal enzyme responsible for apoptosis of renal tubular cells.

Although several in vitro and in vivo approaches have been proposed to reduce cisplatin-induced nephrotoxicity (Nagothu et al., 2005; Wu et al., 2005; Jiang et al., 2007; Lee et al., 2009), the protection they provide is never complete, thus highlighting the need for combined strategies. However, it is unclear whether such approaches would limit the tumoricidal efficacy of cisplatin in cancer cells. We took advantage of the way in which cisplatin is excreted by the kidney to design a strategy specifically aimed at inhibiting apical uptake of cisplatin by renal proximal tubular epithelial cells (RPTECs), without affecting its accumulation and effectiveness in other cells.

Although cisplatin is a substrate of organic cation transporter (OCT) 2 in the basolateral membrane of the proximal tubules, $60 \%$ of cisplatin administered is recovered from lysosomes on the apical membrane, indicating a major role of vesicle cycling in accumulation in RPTECs (Binks and Dobrota, 1989). The relative importance of the roles of the apical and basolateral pathways for the entry of cisplatin into proximal cells can be deduced by analyzing data from the nonfiltering kidney (Binks and Dobrota, 1989).

The apical pole of RPTECs contains proteins found only at this location and which are probably involved in apical vesicle trafficking and extrinsic signal transduction. Inhibition of renal dehydrodipeptidase I (DHP-I), which is located on brush-border cholesterol rafts (Parkin et al., 2001), effectively reduces toxic intracellular accumulation of imipenem (Norrby et al., 1983), cyclosporine A, and tacrolimus (Pérez et al., 2004; Tejedor et al., 2007), and provides specific RPTECs protection against apoptosis induced by these agents. In the present study, we show that cilastatin, a specific inhibitor of brush border-bound renal DHP-I, can provide organ-specific protection against cisplatin-induced nephrotoxicity.

\section{Materials and Methods}

\section{Chemicals}

Cisplatin was obtained from Pharmacia (Barcelona, Spain). Crystalline cilastatin (provided by Merck Sharp and Dohme S.A., Madrid, Spain) was dissolved in cell culture medium at the specified concentrations. A dose of $200 \mu \mathrm{g} / \mathrm{ml}$ was chosen because it is cytoprotective and falls within the reference range for clinical use (Pérez et al., 2004).

\section{Proximal Tubular Primary Cell Culture and HeLa Cell Line Culture}

Porcine RPTECs were obtained as described previously (Pérez et al., 2004). In brief, the cortex was sliced and incubated for $30 \mathrm{~min}$ at $37^{\circ} \mathrm{C}$ with $0.6 \mathrm{mg} / \mathrm{ml}$ collagenase A (Roche Diagnostics $\mathrm{GmbH}$, Roche Applied Science, Penberg, Germany) in Ham's F-12 medium. Digested tissue was then filtered through a metal mesh $(250 \mu \mathrm{m})$, washed three times with Ham's F-12 medium, and centrifuged using an isotonic Percoll gradient (45\%; v/v) at 20,000g for $30 \mathrm{~min}$. Proximal tubules were recovered from the deepest fraction, washed, and resuspended in supplemented Dulbecco's modified Eagle's medium/ Ham's F-12 medium in a 1:1 ratio (with $25 \mathrm{mM}$ HEPES, $3.7 \mathrm{mg} / \mathrm{ml}$ sodium bicarbonate, $2.5 \mathrm{mM}$ glutamine, $1 \%$ nonessential amino acids, $100 \mathrm{U} / \mathrm{ml}$ penicillin, $100 \mathrm{mg} / \mathrm{ml}$ streptomycin, $5 \times 10^{-8} \mathrm{M}$ hydrocortisone, $5 \mathrm{mg} / \mathrm{ml}$ insulin-transferrin-sodium selenite media supplement, and $2 \%$ fetal bovine serum). Proximal tubules were seeded at a density of $0.66 \mathrm{mg} / \mathrm{ml}$ and incubated at $37^{\circ} \mathrm{C}$ in a $95 \%$ air $/ 5 \% \mathrm{CO}_{2}$ atmosphere. Culture medium was renewed every 2 days. RPTECs were used after they had reached confluence $(80 \%)$. HeLa cells were cultured in Dulbecco's modified Eagle's medium supplemented with $10 \%$ fetal bovine serum and $1 \%$ penicillin/streptomycin in a humidified environment with $95 \%$ air $/ 5 \% \mathrm{CO}_{2}$ at $37^{\circ} \mathrm{C}$.

\section{Cell Death Studies}

Cell Morphology. To detect evidence of apoptosis, cell morphology was observed using phase-contrast microscopy. Cell nuclei were visualized after DNA staining with the fluorescent dye 4,6-diamidino-2-phenylindole (DAPI) (Sigma-Aldrich, St. Louis, MO). In brief, cells were seeded on coverslips in a 24 -well plate, fixed in $4 \%$ formaldehyde for $10 \mathrm{~min}$, and permeabilized with $0.5 \%$ Triton X-100. Cells were then rinsed with phosphate-buffered saline (PBS), incubated with DAPI $(12.5 \mu \mathrm{g} / \mathrm{ml})$ for $15 \mathrm{~min}$, and excess dye was removed. Cell imaging was performed with the $40 \times$ PL-APO (apochromatic and flat field correction) 1.25-numerical aperture oil objective of a Leica-SP2 confocal microscope (Leica Microsystems, Heidelberg, Germany). DAPI was excited with a 405-nm laser diode. Emission between 420 and $490 \mathrm{~nm}$ was collected following Leica recommendations. Six fields with $\sim 200$ cells/field were examined in each condition to estimate the percentage of nuclei with apoptosis-like appearance.

Propidium Iodide Flow Cytometry and Cell Detachment Quantification. RPTECs were cultured with $30 \mu \mathrm{M}$ cisplatin in the presence or absence of cilastatin $(200 \mu \mathrm{g} / \mathrm{ml})$ for $24 \mathrm{~h}$. Nonadherent and adherent cells were harvested separately, and both cell populations were resuspended in $2 \%$ paraformaldehyde in PBS for $30 \mathrm{~min}$ at $4^{\circ} \mathrm{C}$. Cells were washed with PBS, permeabilized with PBS/Tween $0.5 \%$ for $15 \mathrm{~min}$ at room temperature, and incubated with $250 \mu \mathrm{g} / \mathrm{ml}$ RNase and $40 \mu \mathrm{g} / \mathrm{ml}$ propidium iodide (PI; Sigma-Aldrich) for $45 \mathrm{~min}$ at room temperature (Pérez et al., 2004). Assay samples were analyzed by flow cytometry with a FACScan equipped with a single argon ion laser (Becton Dickinson, Franklin Lakes, NJ) using standard Lysis II software (Becton Dickinson). Detached cells were quantified by flow cytometry (FACScan). Side scatter, forward scatter, and FL2 fluorescence were collected. FL2-A and FL2-W were used to identify and exclude doublets from the analysis.

Nucleosomal Quantification. To evaluate DNA fragmentation in the context of apoptosis, RPTECs were incubated under specific conditions for $24 \mathrm{~h}$. At the end of this period RPTECs were lysed and centrifuged at $200 \mathrm{~g}$ for $10 \mathrm{~min}$ to remove cell debris. DNA and histones present in the soluble fraction were quantified using an enzyme-linked immunosorbent assay cell death kit (Boehringer Mannheim). Histone and DNA present in mononucleosomes and oligonucleosomes in the cytoplasmic fraction of cell lysates were detected by a sandwich enzyme immunoassay with antihistone and anti-DNA-peroxidase antibodies as described previously (Pérez et al., 2004).

Caspase Activity Assay. Caspase 3, caspase 8, and caspase 9 activities were determined using the substrates DEVD- $p$ NA, IETD$p \mathrm{NA}$, and LEHD- $p \mathrm{NA}$, respectively, following the protocols of the 
APOPCYTO Caspase-3, Caspase-8, and Caspase-9 Colorimetric Assay Kits from MBL Medical \& Biological Laboratories Co., Ltd. (Nagoya, Japan). At 24 or $48 \mathrm{~h}$ of treatment, both adherent and nonadherent cells were harvested, resuspended in $120 \mu \mathrm{l}$ of lysis buffer (MBL Medical \& Biological Laboratories Co., Ltd.), and incubated at $4^{\circ} \mathrm{C}$ for $10 \mathrm{~min}$ followed by centrifugation at $10,000 \mathrm{~g}$ for 5 $\mathrm{min}$. Aliquots $(50 \mu \mathrm{l})$ of supernatants were removed and placed in a 96-well microplate. Substrate was added, and the microplate was incubated at $37^{\circ} \mathrm{C}$ for $2 \mathrm{~h}$. $p$ NA light absorption was quantified using a spectrophotometer plate reader at $405 \mathrm{~nm}$ and compared with a linear standard curve generated on the same microplate.

Measurement of Annexin V/Fluorescein Isothiocyanate Staining. Annexin staining was determined using confocal microscopy. RPTECs were treated for 12,24 , or $48 \mathrm{~h}$ with $30 \mu \mathrm{M}$ cisplatin in the presence or absence of cilastatin $(200 \mu \mathrm{g} / \mathrm{ml})$. Both adherent and nonadherent cells were collected and centrifuged at $1500 \mathrm{rpm}$ for $5 \mathrm{~min}$, rinsed twice with binding buffer (10 mM HEPES, $\mathrm{pH} 7.4,140$ $\mathrm{mM} \mathrm{NaCl}$, and $2.5 \mathrm{mM} \mathrm{CaCl}_{2}$ ), resuspended at a final density of 1 to $2 \times 10^{6}$ cells $/ \mathrm{ml}$, and incubated with $5 \mu \mathrm{l}$ of annexin V/fluorescein isothiocyanate (FITC) (Biotium, Hayward, CA) for $15 \mathrm{~min}$ at room temperature in the dark. Next, cells were fixed in $2 \%$ formaldehyde for $15 \mathrm{~min}$ at room temperature, washed, and placed on a glass coverslip to be visualized. Microscopy was performed using a LeicaSP2 confocal microscope (Leica Microsystems). Different measurements of annexin V/FITC fluorescence were assessed with Leica Confocal Software LCS-1537 (Leica Microsystems).

Determination of Lactate Dehydrogenase Release. Lactate dehydrogenase (LDH) release from RPTECs was measured in the culture media after treatment with cisplatin in the presence or absence of cilastatin $(200 \mu \mathrm{g} / \mathrm{ml})$ for 24 and $48 \mathrm{~h}$. LDH was measured automatically in a modular AutoAnalyzer Cobas 711 (Roche, Basel, Switzerland). $\mathrm{LDH}$ release was expressed in relative terms to total LDH released by treatment with $0.1 \%$ Triton X-100 (100\% release).

Cell Viability Assay. Cell survival assay relies on the capacity of cells to reduce 3-(4,5-dimethylthiazol-2-yl)-2,5-diphenyltetrazolium (MTT) (Calbiochem, San Diego, CA) to colored formazan in metabolically active cells. RPTECs or HeLa cells were seeded and incubated with cisplatin alone or in combination with cilastatin. Twenty-four, 48 , or $72 \mathrm{~h}$ later, $0.5 \mathrm{mg} / \mathrm{ml}$ MTT was added, and plates were incubated for $3 \mathrm{~h}$ in the dark at $37^{\circ} \mathrm{C}$, and $100 \mu \mathrm{l}$ of $50 \%$ dimethyl formamide in $20 \%$ SDS, pH 4.7 , was added. Plates were incubated at $37^{\circ} \mathrm{C}$ overnight, and absorbance was measured at $595 \mathrm{~nm}$. All the assays were performed in triplicate.

\section{Cell Viability: Quantification of Colony-Forming Units}

RPTECs were treated for $24 \mathrm{~h}$ with cisplatin in the presence or absence of cilastatin $(200 \mu \mathrm{g} / \mathrm{ml})$. Adherent cells were washed in saline serum, harvested with trypsin/EDTA, seeded in Petri dishes $(100 \mathrm{~mm})$, and cultured for 7 days in drug-free complete medium. Surviving adherent cells were fixed for 5 min with $5 \%$ paraformaldehyde/PBS and stained with $0.5 \%$ crystal violet $/ 20 \%$ methanol for 2 min. Excess dye was rinsed with PBS. Finally, the intracellular dye was eluted with $50 \%$ ethanol $/ 50 \%$ sodium citrate $0.1 \mathrm{M}, \mathrm{pH} 4.2$, and quantified by spectrometry at $595 \mathrm{~nm}$.

\section{Mitochondrial Membrane Potential Assay}

Changes in mitochondrial transmembrane potential $(\Delta \Psi \mathrm{m})$ were measured using the MitoProbe JC-1 Assay Kit for Flow Cytometry (Invitrogen, Carlsbad, CA) according to the manufacturer's protocol. JC-1 is a cationic dye that exhibits potential-dependent accumulation in mitochondria, indicated by a fluorescence emission shift from green $(\sim 529 \mathrm{~nm})$ to red $(\sim 590 \mathrm{~nm})$. Consequently, mitochondrial depolarization is seen as a shift to lower JC-1 red fluorescence accompanied by an increase in JC-1 green fluorescence.

Data analyses were performed using WinMDI software (http:// www.cyto.purdue.edu/flowcyt/software/winmdi.htm) by measuring both the green $(530 \pm 15 \mathrm{~nm})$ and red $(585 \pm 21 \mathrm{~nm})$ JC-1 fluores- cence with an FACScan equipped with a single argon ion laser (Becton Dickinson). At least 10,000 events were acquired per sample. The membrane potential disruptor, carbonyl cyanide 3-chlorophenylhydrazone (CCCP; supplied with the kit, $50 \mu \mathrm{M}$ final concentration), was used as a positive control.

\section{Cytochrome $c$ Release}

Release of cytochrome $c$ from mitochondria into cytosol was measured using Western blot analysis. RPTECs treated for $24 \mathrm{~h}$ with 10 to $30 \mu \mathrm{M}$ cisplatin in the presence or absence of cilastatin $(200 \mu \mathrm{g} / \mathrm{ml})$ were harvested, washed once with ice-cold PBS, and gently lysed for $10 \mathrm{~min}$ in ice with $90 \mu \mathrm{l}$ of lysis buffer $(250 \mathrm{mM}$ sucrose, $80 \mathrm{mM} \mathrm{KCl}$, $500 \mu \mathrm{g} / \mathrm{ml}$ digitonin, $1 \mathrm{mM}$ dithiothreitol, $0.1 \mathrm{mM}$ phenylmethylsulfonyl fluoride, and protease inhibitors in PBS). Cell lysates were centrifuged at $12,000 \mathrm{~g}$ at $4^{\circ} \mathrm{C}$ for $5 \mathrm{~min}$ to obtain the supernatants (cytosolic extract free of mitochondria) and the pellets (fractions containing the mitochondria), which were resuspended in $90 \mu \mathrm{l}$ of lysis buffer. Equal amounts of protein were loaded $(50 \mu \mathrm{g}$ in each lane) and electrophoresed on $15 \%$ polyacrylamide gels as described previously (Gallego-Delgado et al., 2006).

Goat polyclonal antibody against $\mathrm{C}$ terminus of cytochrome $c$ of human origin (Santa Cruz Biotechnology, Inc., Santa Cruz, CA) was used at 1:500. The membranes were also probed with goat polyclonal antibody against a peptide of voltage-dependent anion-selective channel 1 of human origin (1:500; Santa Cruz Biotechnology, Inc.) for mitochondrial fractions and monoclonal anti- $\alpha$-tubulin Clone B-5-1-2 Mouse Ascites Fluid (mouse IgG1 isotype) antibodies (1:10,000; Sigma-Aldrich) for cytosolic fractions as internal controls for the technique. Proteins were visualized with the enhanced chemiluminescence detection system (GE Healthcare, Little Chalfont, Buckinghamshire, UK).

\section{Cellular Cisplatin Uptake and Estimation of DNA-Bound Platinum. Platinum-Biomolecule Speciation Analysis}

RPTECs incubated for $24 \mathrm{~h}$ with increasing concentrations of cisplatin in the presence or absence of cilastatin $(200 \mu \mathrm{g} / \mathrm{ml})$ were scraped and lysed in $400 \mu \mathrm{l}$ of lysis buffer at $70^{\circ} \mathrm{C}[2.22 \%(\mathrm{w} / \mathrm{v}) \mathrm{SDS} ; 19.33 \%$ (v/v) glycerol $(87 \% \mathrm{v} / \mathrm{v}) ; 790 \mathrm{mM}$ Tris $\mathrm{HCl}, \mathrm{pH} 6.8$, in $\mathrm{dH}_{2} \mathrm{O}$, phenylmethylsulfonyl fluoride, and protease inhibitors). Cell lysates were heated at $100^{\circ} \mathrm{C}$ for $5 \mathrm{~min}$, homogenized in ice, and centrifuged at $12,000 \mathrm{~g}$ for $5 \mathrm{~min}$ at $4^{\circ} \mathrm{C}$. The supernatant was analyzed for total protein content and cisplatin (as platinum, Pt). Alternatively, for DNA/Pt measurements, RPTECs and HeLa cells were treated for $24 \mathrm{~h}$ with cisplatin in the presence or absence of cilastatin (200 $\mu \mathrm{g} / \mathrm{ml}$ ), and both nonadherent cells and adherent cells were collected, rinsed with PBS, and centrifuged at 13,000 rpm for $10 \mathrm{~min}$. Cell pellet was resuspended in PBS/lysis buffer (v/v, $20 \mathrm{mM}$ EDTA, pH 8, $0.5 \%$ Triton $\mathrm{X}-100$, and $5 \mathrm{mM}$ Tris, $\mathrm{pH} 8$ ) and incubated $30 \mathrm{~min}$ at $37^{\circ} \mathrm{C}$ with $10 \mathrm{mg} / \mathrm{ml}$ RNase A (Invitrogen). Samples were then treated with proteinase $\mathrm{K}(10 \mathrm{mg} / \mathrm{ml}$; Applied Biosystems, Foster City, CA) at $55^{\circ} \mathrm{C}$ for $3 \mathrm{~h}$ and then extracted with phenol (equilibrated with Tris, $\mathrm{pH}$ 8.0; Sigma-Aldrich) by shaking gently for 2 min. After centrifugation $(12,000 \mathrm{rpm})$, the phases were separated, and the aqueous phase was isolated. The extraction was repeated twice with phenol-chloroform/isoamyl alcohol (1-24:1, v/v) and finally with chloroform/isoamyl alcohol $(24: 1, \mathrm{v} / \mathrm{v})$. The DNA in the aqueous phase was precipitated by the addition of $100 \%$ ethanol at $-20^{\circ} \mathrm{C}$ and $3 \mathrm{M}$ sodium acetate, $\mathrm{pH} 5.3$, followed by incubation overnight at $-80^{\circ} \mathrm{C}$. The DNA was collected by centrifugation $(12,000 \mathrm{rpm}, 15$ $\mathrm{min}$ ), washed with $1 \mathrm{ml}$ of $70 \%$ ethanol, dried, and resuspended in $300 \mu \mathrm{l}$ of $10 \mathrm{mM}$ Tris, $\mathrm{pH} 7.6$, and $0.1 \mathrm{mM}$ EDTA in sterile water. The DNA was quantitatively estimated from the absorption at $260 \mathrm{~nm}$ using a NanoDrop UV-visible instrument (Nucliber, Madrid, Spain).

$\mathrm{Pt}$ content in cell-soluble fraction or DNA was measured using a Quadrupole Thermo X-series inductively coupled plasma/mass spectrometry (ICP/MS) (Thermo Fisher Scientific, Waltham, MA) equipped with a Meinhard nebulizer (Meinhard Glass Products, 
Golden, CO), a Fassel torch, and an Impact Bead Quartz spray chamber (both by Glass Expansion, West Melbourne, VIC, Australia) cooled by a Peltier system (Peltier Systems, LLC, Athens, TX). Before the analysis, samples were 5 -fold diluted in aqueous solutions containing $2 \% \mathrm{HCl}$, which made it possible to stabilize Pt. Quantification was performed by external calibration; the internal standard was iridium (Ir), added in a final concentration of $20 \mu \mathrm{g} / \mathrm{l}$ to both samples and standards. ICP/MS measurements were acquired in continuous mode, monitoring $\mathrm{m} / \mathrm{z}^{194} \mathrm{Pt},{ }^{195} \mathrm{Pt}$, and ${ }^{191} \mathrm{Ir}$, and results were expressed as (microgram Pt/gram protein) and (microgram Pt/gram DNA).

Pt-Biomolecule Speciation Analysis. Pt-biomolecules were analyzed by high-performance liquid chromatography/ICP/MS. Supernatants were chromatographically separated using a size exclusion (SEC) Superdex 75 10/300 GL column (Amersham), which presents a nominal separation between 3 and $70 \mathrm{kDa}$. Ten millimolar Tris- $\mathrm{NO}_{3}$ and $25 \mathrm{mM} \mathrm{NaCl}, \mathrm{pH} 7.42$, was used as the mobile phase at a flow rate of $0.8 \mathrm{ml} / \mathrm{min}$. The SEC column was coupled to an ICP/MS, and ${ }^{195} \mathrm{Pt}$ was monitored. Samples were 1:1 diluted with the mobile phase before analysis, and $100 \mu \mathrm{l}$ of each sample was injected into the chromatographic system through a $0.22-\mu \mathrm{m}$ nylon filter. In parallel, the SEC column was calibrated using several proteins with different molecular masses: blue dextran $(>2000 \mathrm{kDa})$, bovine serum albumin $(66 \mathrm{kDa})$, carbonic anhydrase $(29 \mathrm{kDa})$, cytochrome $c(12.4 \mathrm{kDa})$, and aprotinin $(6.5 \mathrm{kDa})$ (Sigma-Aldrich), with a UV-visible detector. These molecular masses can be used as a reference for the separation capacity of the column, although it should be borne in mind that secondary interactions with the stationary phase could alter retention times.

\section{DHP-I and DHP-IV Activity Assays}

RPTECs or HeLa cells were incubated overnight with Gly-Phe- $p$ nitroanilide (DHP-I substrate; Sigma-Aldrich) $1 \mathrm{mM}$ in PBS for DHP-I activity determination, or with Gly-Pro- $p$-nitroanilide (DHP-IV substrate; Sigma-Aldrich) $1 \mathrm{mM}$ for DHP-IV activity determination. Both activities were measured in the presence or absence of cilastatin $(200 \mu \mathrm{g} / \mathrm{ml}) . p$-Nitroanilide was quantified in aliquots from supernatants by measuring $410-\mathrm{nm}$ absorbance.

\section{Cisplatin-Induced Expression of Apoptotic Genes in RPTECs}

Tumor necrosis factor (TNF) $\alpha$, Fas, and Fas ligand (Fas-L) gene expression was analyzed by real-time polymerase chain reaction (PCR). RPTECs were cultured with $30 \mu \mathrm{M}$ cisplatin in the presence or absence of cilastatin $(200 \mu \mathrm{g} / \mathrm{ml})$ for $24 \mathrm{~h}$. Total RNA was isolated by the TRIzol method (Invitrogen) from RPTECs and processed according to the protocol provided by the manufacturer. In brief, $1 \mu \mathrm{g}$ of RNA was reverse-transcribed with High-Capacity cDNA Archive Kit (Applied Biosystems). Real-time PCR was performed on a TaqMan ABI 7700 Sequence Detection System (Applied Biosystems) using heatactivated Taq DNA polymerase (Amplitaq Gold) (Lazaro et al., 2005). For all the quantitative cDNA analyses, the $\triangle \mathrm{CT}$ technique was applied (Lazaro et al., 2005). Ribosomal phosphoprotein large PO subunit (RPLPO) served as housekeeping gene and was amplified in parallel with the genes of interest. The expression of each target gene was normalized to RPLPO. Primer sequences for porcine TNF $\alpha$, Fas, Fas-L, and RPLPO were synthesized commercially (Invitrogen) and are available on request. All the measurements were performed in duplicate. Controls consisting of $\mathrm{ddH}_{2} \mathrm{O}$ were negative in all the runs.

\section{Immunofluorescence Localization of Fas-L}

RPTECs grown on sterile crystal coverslips were treated with 30 $\mu \mathrm{M}$ cisplatin in the presence or absence of cilastatin $(200 \mu \mathrm{g} / \mathrm{ml})$ for 0.5 and $2 \mathrm{~h}$. Cells were washed with PBS and fixed in $4 \%$ formaldehyde in PBS for $10 \mathrm{~min}$. Cells were washed twice in PBS and blocked for $1 \mathrm{~h}$ in bovine serum albumin $1 \% / \mathrm{PBS} / \mathrm{Tw}$ ween $0.1 \%$ at $37^{\circ} \mathrm{C}$. Cells then were incubated with rabbit polyclonal antibody against a peptide of $\mathrm{C}$ terminus of Fas-L of human origin (1:50; Santa Cruz Biotechnology, Inc.) for $1 \mathrm{~h}$ at $37^{\circ} \mathrm{C}$ followed by incubation with FITC-conjugated secondary antibody (donkey antirabbit, 1:200; Jackson ImmunoResearch Laboratories Inc., West Grove, PA) in blocking solution for another hour at $37^{\circ} \mathrm{C}$. Cell nuclei were counterstained with DAPI ( $5 \mu \mathrm{g} / \mathrm{ml}$; Sigma-Aldrich). The absence of primary antibody was the negative control. After washing, cells were mounted in fluorescent mounting medium (Dako North America, Inc., Carpinteria, CA), and Fas-L immunolocalization was examined with the $20 \times$ PL-APO 0.7-numerical aperture objective of a Leica-SP2 confocal microscope (Leica Microsystems). Different intensity measurements were assessed with the Leica Confocal Software LCS-1537 (Leica Microsystems).

\section{Statistical Methods}

Quantitative variables were summarized as the mean \pm S.E.M. Differences were considered statistically significant for bilateral $\alpha$ values less than 0.05 . Factorial analysis of variance (ANOVA) was used when more than one factor was considered. When a single factor presented more than two levels, a post hoc analysis (least significant difference) was performed if the model showed significant differences between factors. When demonstrative results are shown, they represent a minimum of at least three repeats. When possible, a quantification technique (e.g., densitometry, dye recovery) has been used to illustrate reproducibility.

\section{Results}

Cilastatin Reduces Cisplatin-Induced Proximal Tubular Cell Death. Cisplatin induces time- and dosedependent cell death on primary culture of RPTECs. When RPTECs are exposed to increasing concentrations of cisplatin for $3,6,24$, and $48 \mathrm{~h}$, direct observation by phase microscopy shows cell rounding and detachment from the plate. Cilastatin significantly reduced the observed impact for every cisplatin concentration and exposure time studied (Fig. 1A).

However, cisplatin-induced cell death causes an early detachment of damaged cells from the plate. We studied the characteristics of nonadherent cells in terms of size, complexity, and PI staining by flow cytometry after 24-h exposure to increasing doses of cisplatin \pm cilastatin. Figure $1 \mathrm{~B}$ shows the flow cytometry histogram for PI staining (FL2-H) of nonadherent cells from control plates, $30 \mu \mathrm{M}$ cisplatin-treated plates, or $30 \mu \mathrm{M}$ cisplatin plus cilastatintreated plates. A relevant span of PI fluorescence was observed because both diploid and hypodiploid populations are recovered in the supernatant. Figure $1 \mathrm{C}$ is a quantification of these nonadherent cells. Cilastatin caused a $70 \%$ reduction in cell detachment when $30 \mu \mathrm{M}$ cisplatin was used. Cell protection becomes statistically significant at cisplatin concentrations greater than $10 \mu \mathrm{M}$.

Qualitative estimation of apoptotic cell death was obtained in adherent cells stained with DAPI (Fig. 1D). Incubation with $30 \mu \mathrm{M}$ cisplatin led to cell shrinkage with significant nuclear condensation, fragmentation, and formation of apoptotic-like bodies (see arrows). Figure $1 \mathrm{E}$ shows a quantification of apoptotic nuclei in adherent cells. Cilastatin reduced nuclear damage by $64 \%$.

We quantified the functional impact of cisplatin treatment on cell survival by measuring the percentage of adherent cells still able to reduce MTT to formazan after exposure to increasing doses of cisplatin. Coincubation with cilastatin 
A

0

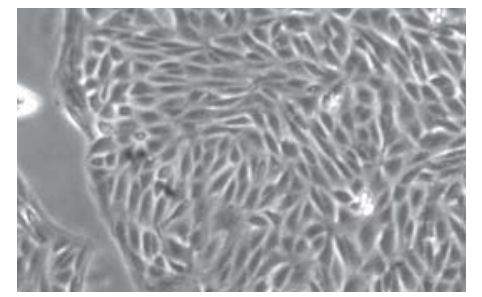

10

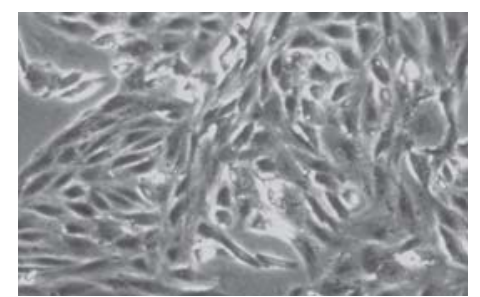

30

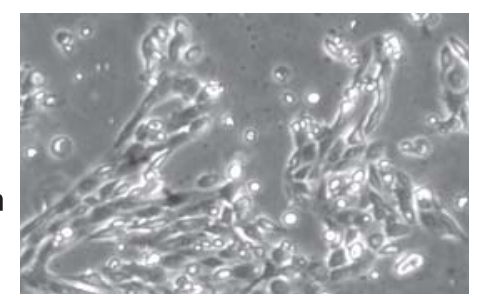

D

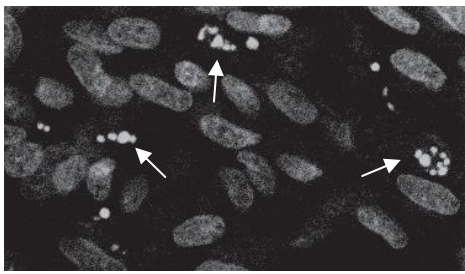

Cisplatin $30 \mu \mathrm{M}$
Cilastatin
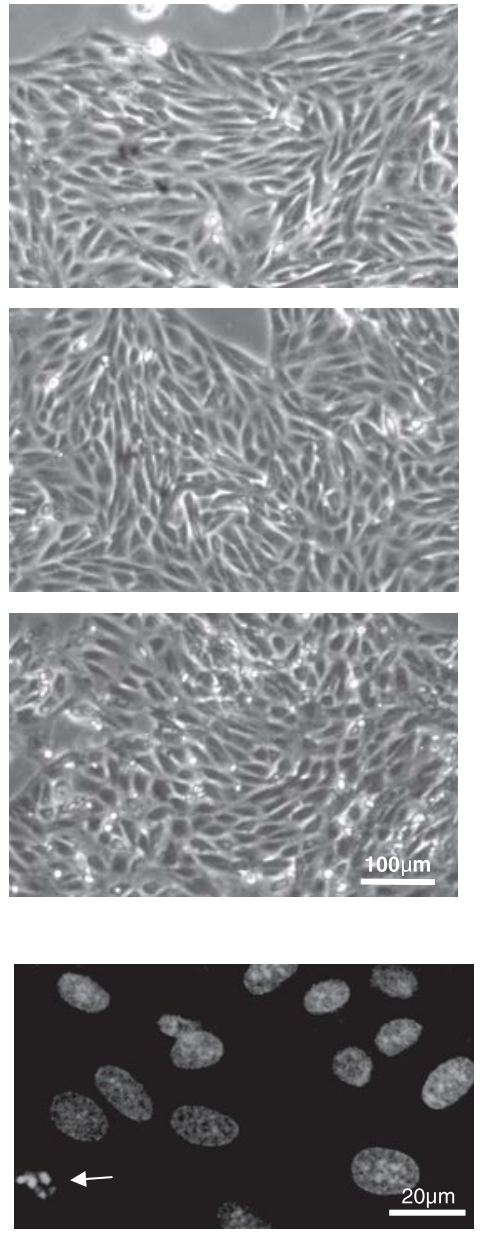

Cisplatin $30 \mu \mathrm{M}+$ cilastatin
B

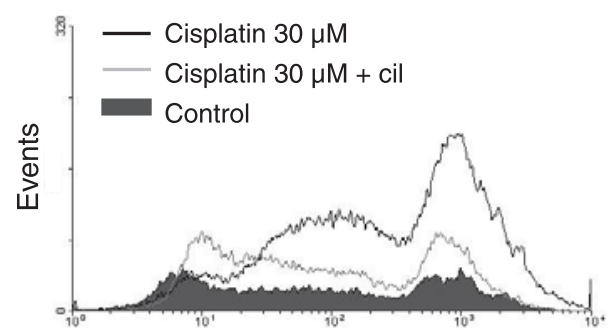

C

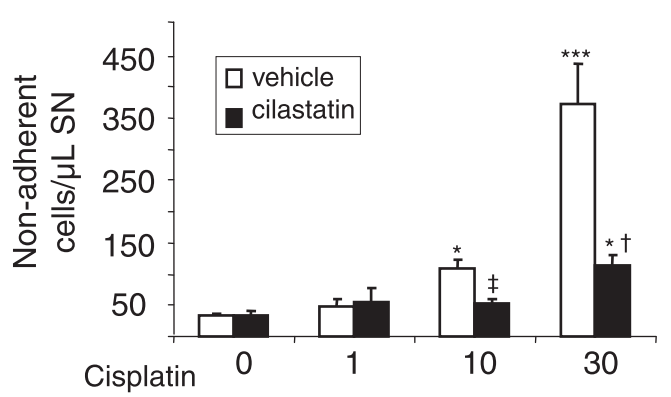

$(\mu \mathrm{M})$

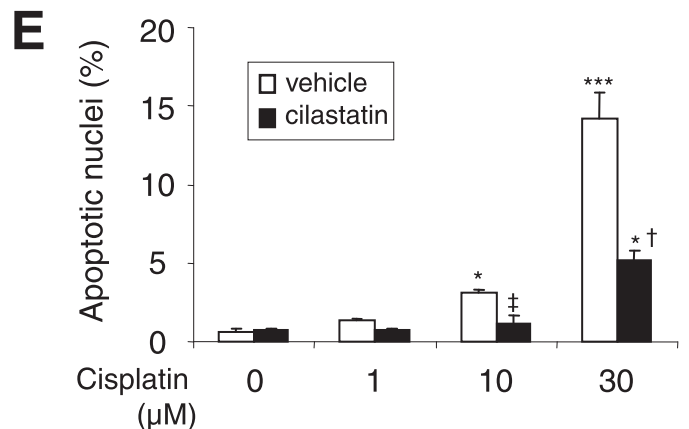

Fig. 1. Effects of cilastatin on RPTECs morphology during treatment with cisplatin. RPTECs were cultured in the presence of cisplatin (1, 10, and 30 $\mu \mathrm{M})$ and cisplatin + cilastatin $(200 \mu \mathrm{g} / \mathrm{ml})$ for $24 \mathrm{~h}$. A, phase-contrast photomicrographs are shown (representative example of at least three independent experiments; original magnification, $40 \times$ ). B, flow cytometry analysis: nonadherent cells were harvested, fixed, and stained with PI for DNA content. FL2-H signal is presented for the three studied conditions. C, the effect of cilastatin on cisplatin-induced detachment of RPTECs was measured by flow cytometry and determined by counting the number of cells in an equal volume of buffer. D, nuclear staining with DAPI. Adherent RPTECs treated with $30 \mu \mathrm{M}$ cisplatin and $30 \mu \mathrm{M}$ cisplatin $+200 \mu \mathrm{g} / \mathrm{ml}$ cilastatin were stained with DAPI to study whether apoptotic-like nuclear morphology was present. Arrows point to fragmented, apoptotic nuclei. E, quantitative approach to the images presented in D. Data are represented as the mean \pm S.E.M. of at least three separate experiments. ANOVA models, $P<0.0001$. *, $P<0.05 ; * * *, P<0.0001$ versus control; $\ddagger, P<0.05$; $\dagger, P<0.0001$ versus same data without cilastatin.

doubles cell survival in every condition analyzed. Statistical significance was obtained for incubations with cilastatin in $10 \mu \mathrm{M}$ cisplatin and more than $24 \mathrm{~h}$ (Fig. 2A).

Analysis of nucleosomal DNA fragmentation and migration from nuclei to cytosol is presented in Fig. 2B. RPTECs exposed to cisplatin for $24 \mathrm{~h}$ present a dose-dependent increase in nucleosomes recovered from cytosol, which were reduced by cilastatin treatment.

To better characterize the apoptosis process triggered on RPTECs by cisplatin, we quantified annexin V/FITC staining and caspase 3 , caspase 8 , and caspase 9 activation. Cisplatin caused an increase in annexin V/FITC staining that reached a maximum at $24 \mathrm{~h}$ and persisted until $48 \mathrm{~h}$ (Fig. 2C). Confocal microscopy showed that annexin V was mainly localized to the outer leaflet of the plasma membrane (data not shown). Cilastatin coincubation showed less annexin V staining, with a reduction of 53\% (Fig. 2C).
Because apoptosis is generally followed by secondary necrosis, which is associated with the leakage of plasma membrane, we also measured the release of $\mathrm{LDH}$ from the cells in the medium (Fig. 2D). At $24 \mathrm{~h}, 30 \mu \mathrm{M}$ cisplatin incubation caused $6 \%$ release of total $\mathrm{LDH}$ cellular content (as estimated from Triton X-100 treatment). This percentage increased to $30 \%$ at $48 \mathrm{~h}$. Necrotic cell death was not modified by cilastatin coincubation, indicating that cilastatin reduction of cisplatin-induced cell death was specific for apoptosis. Cisplatin-induced apoptosis was further confirmed by caspase 9 , caspase 8 , and caspase 3 activities. Figure 3, A through C, shows that increasing doses of cisplatin caused significant activation of caspase 8 and caspase 3, with caspase 9 less evident. Cilastatin reduced caspase 8 and caspase 3 activations at 24 and 48 h (for caspase 3, Fig. 3D). Cilastatin alone had no effect on any of the previously reported data. 
A
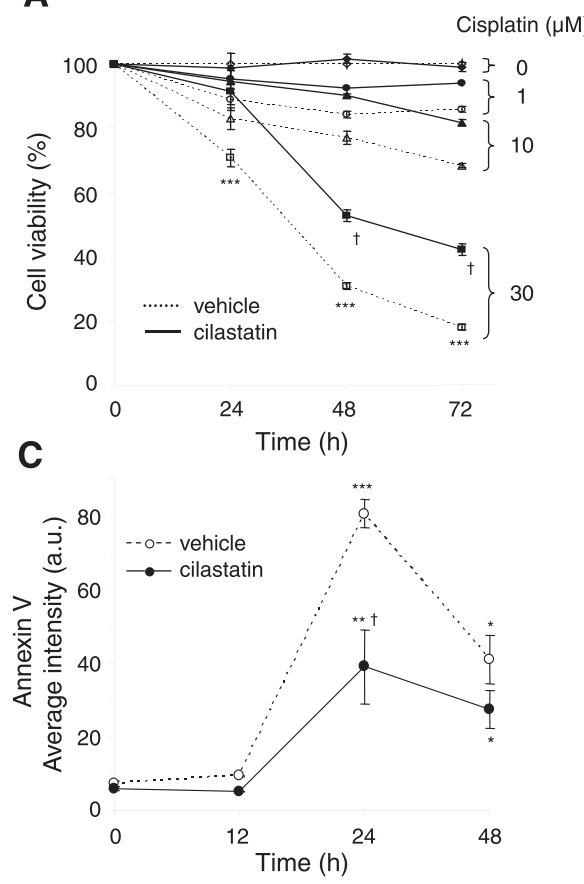

B

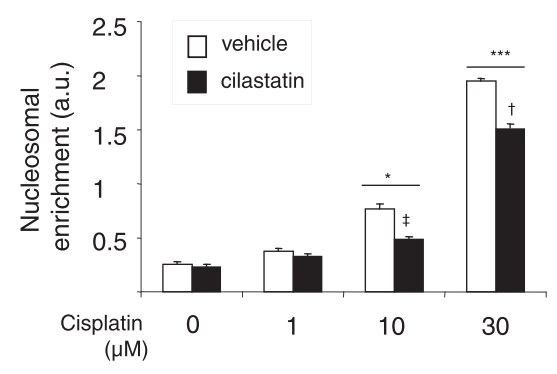

D

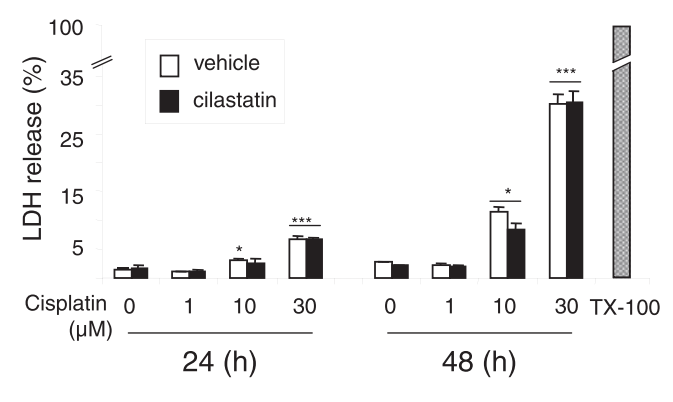

Fig. 2. Cilastatin attenuates cisplatin-induced apoptosis but not necrosis. RPTECs were exposed to cisplatin (1, 10, and $30 \mu \mathrm{M})$ and cisplatin + cilastatin $(200 \mu \mathrm{g} / \mathrm{ml})$ for indicated times. A, effect of cilastatin on cisplatin-induced loss of cell viability determined by the ability to reduce MTT (see Materials and Methods). Results are expressed as the percentage of the value obtained relative to control (without cisplatin and cilastatin). ANOVA model, $P<0.0001$; cisplatin dose,$P<0.0001$; cilastatin effect, $P<0.0001$; time effect, $P<0.0001$; cilastatin $\times$ time, N.S. $* * *, P<0.0001$ all the data versus control (except $30 \mu \mathrm{M}+$ cilastatin, $10 \mu \mathrm{M}+$ cilastatin, and $1 \mu \mathrm{M} \pm$ cilastatin at $24 \mathrm{~h} ; P=\mathrm{N} . \mathrm{S}$.) $\dagger, P<0.0001$ every condition + cilastatin versus same condition without cilastatin (except $10 \mu \mathrm{M}+$ cilastatin and $30 \mu \mathrm{M}+$ cilastatin at $24 \mathrm{~h} ; P<0.05$ ). B, oligonucleosomes at $24 \mathrm{~h}$ were quantified in the cell-soluble fraction and detected with an enzyme-linked immunosorbent assay kit. C, phosphatidylserine externalization was determined in nonadherent cells by annexin V/FITC staining and confocal microscopy quantification. D, effect of cilastatin in cisplatin-induced LDH release. Data are presented as percentage of total LDH release obtained by Triton X-100 cell treatment. Data are represented as the mean \pm S.E.M. of at least three separate experiments. ANOVA models, $P<0.0001$. *, $P<0.05 ; * *, P<0.01 ; * * *, P<0.0001$ versus control; $\neq, P<0.05 ; \dagger, P<0.0001$ versus same data without cilastatin.

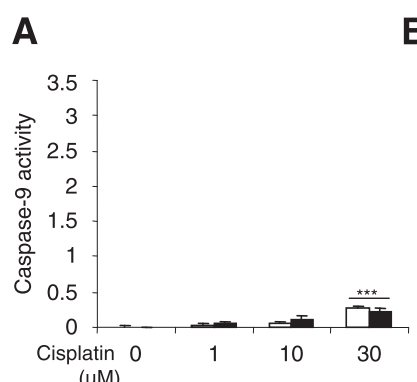

$(\mu \mathrm{M})$
B

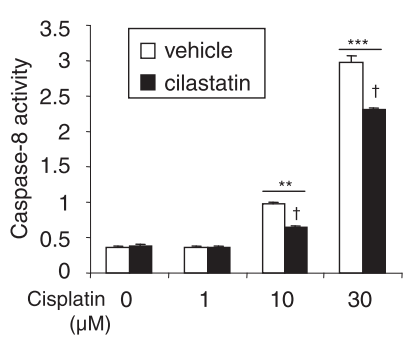

C

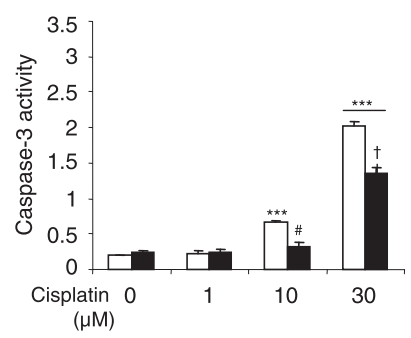

Fig. 3. Effect of cisplatin and cilastatin on caspase activity. A, B, and C show the activation of caspase 9 , caspase 8 , and caspase 3 , respectively, with increasing doses of cisplatin for $24 \mathrm{~h}$, as well as the effect of cilastatin $(200 \mu \mathrm{g} /$ $\mathrm{ml}$ ). ANOVA model, $P<0.0001 . * *, P<$ $0.01 ; * * *, P<0.0001$ versus control; \#, $P<0.01 ; \dagger, P<0.0001$ versus same data without cilastatin. $\mathrm{D}$, time course activation of caspase 3 with different doses of cisplatin $\pm 200 \mu \mathrm{g} / \mathrm{ml} \mathrm{cila-}$ statin. Data are represented as the mean \pm S.E.M. of four experiments. ANOVA model, $P<0.0001$; cisplatin dose, $P<0.0001$; cilastatin effect, $P<$ 0.0001 ; cilastatin $\times$ cisplatin, $P<$ 0.0001. **, $P<0.01 ; * * *, P<0.0001$ versus control; \#, $P<0.01$; †, $P<0.0001$ versus same data without cilastatin.
Cilastatin Reduces Cisplatin-Induced Mitochondrial Damage. Mitochondrial damage is a central event in the cytotoxic and nephrotoxic activity of cisplatin. Comparison of control cells with cisplatin-treated RPTECs showed ev- ident membrane depolarization (decrease in red fluorescence; FL2-H) with no changes in green fluorescence (FL1-H) (Fig. 4A). Cilastatin alone did not have a significant effect on $\Delta \psi \mathrm{m}$. However, cilastatin partially pre- 
A

C

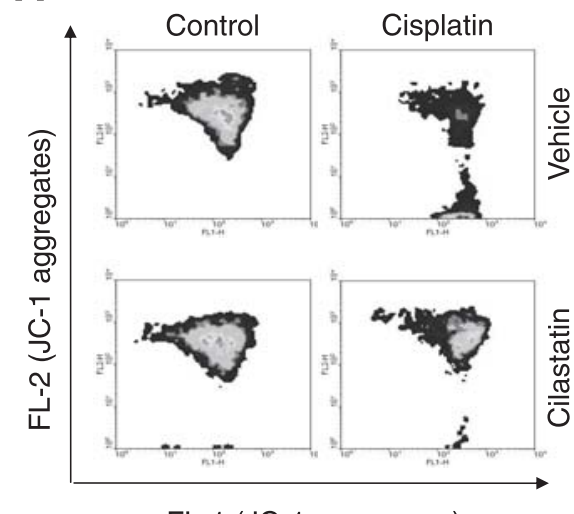

B

FL-1 (JC-1 monomers)

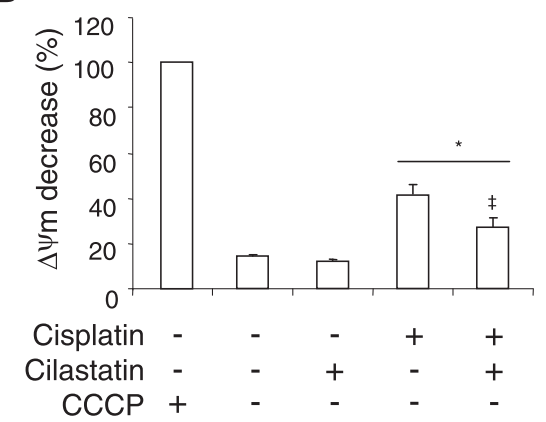

PARTICULATE

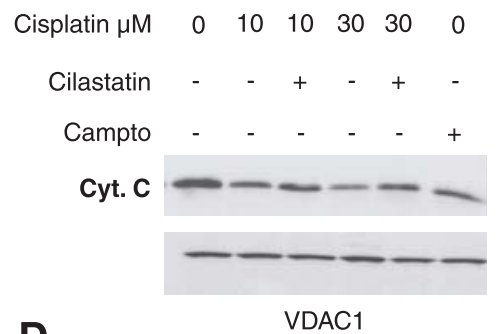

D

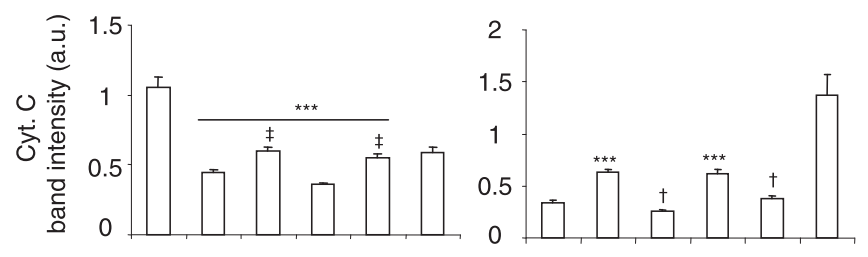

Fig. 4. Effect of cilastatin on cisplatin-induced mitochondrial injury. A, changes in $\Delta \Psi \mathrm{m}$ were analyzed by flow cytometry after staining with JC-1. RPTECs were incubated with $30 \mu \mathrm{M}$ cisplatin with or without $200 \mu \mathrm{g} / \mathrm{ml}$ cilastatin for $24 \mathrm{~h}$. Results are presented as contour plots. B, quantification of the results of four independent experiments. As a positive control, cells were treated for 5 min with $50 \mu \mathrm{M}$ CCCP. Decrease in red fluorescence with CCCP was considered as $100 \%$ of the change in $\triangle \Psi \mathrm{m}$. Data are the mean \pm S.E.M. ANOVA model, $P<0.0001 . *, P<0.05$ versus control; $\neq, P<0.05$ versus same data without cilastatin. C, Western blot analysis of cytochrome $c$ of cytosolic and mitochondrial fractions of RPTECs treated with 10 and $30 \mu \mathrm{M}$ cisplatin in the presence or absence of $200 \mu \mathrm{g} / \mathrm{ml}$ cilastatin for $24 \mathrm{~h}$. Voltage-dependent anion-selective channel and $\alpha$-tubulin antibodies were used as internal loading controls for mitochondrial (particulate) and cytosolic fractions, respectively. Camptothecin (Campto), $50 \mu \mathrm{g} / \mathrm{ml}$, was used as a positive control. D, the values corresponding to normalized cytochrome $c$ band intensity. Mean \pm S.E.M. of three separate experiments. ANOVA model, $P<0.0001$. ***, $P<0.0001$ compared with control group; $\ddagger, P<0.05 ; \dagger, P<0.0001$ versus same data without cilastatin.

vented $\Delta \psi \mathrm{m}$ loss when RPTECs were simultaneously exposed to cisplatin and cilastatin. The results were quantified and expressed in relative terms compared with total depolarization induced by CCCP (Fig. 4B).

To further investigate the role of the mitochondria in cilastatin-mediated effect, cisplatin action with and without cilastatin on cytochrome $c$ release was studied. As presented in Fig. 4C, the subcellular distribution of cytochrome $c$ between mitochondria (particulate) and cytosol reveals a significant degree of protection, indicating that cilastatin improves the cell viability of RPTECs (Fig. 4, C and D).

Cilastatin Improves Long-Term Recovery and Cell Viability in RPTECs after Exposure to Cisplatin. To know the long-term viability of surviving RPTECs after 24-h exposure to cisplatin, we tested the ability of those cells to proliferate into new cell colonies. Colony-forming units (CFUs) were quantified as specified under Materials and Methods. The CFU count decreased dramatically after $24 \mathrm{~h}$ of treatment with cisplatin, and this decrease was clearly dosedependent (Fig. 5A). When RPTECs were exposed to cisplatin and cilastatin simultaneously, the number of CFUs was significantly greater after 7 days of recovery at every cisplatin concentration studied. The intracellular dye was extracted, and absorbance was quantified at $595 \mathrm{~nm}$ (Fig. 5B).

Cilastatin Reduces Intracellular Accumulation of Cisplatin. Effects in DNA-Bound Pt. The nephrotoxicity of cisplatin largely depends on the intracellular concentration reached, more specifically on the DNA-bound Pt. Dosedependent cisplatin accumulation was measured in the soluble fraction of RPTECs after 24-h incubation (Fig. 6A). Because of the early cell detachment detected previously, we decided also to quantify DNA-bound Pt in adherent cells and nonadherent cells after 24 -h incubation with $30 \mu \mathrm{M}$ cisplatin (Fig. 6B). Cilastatin caused a significant reduction (24\%) in $\mathrm{Pt}$ recovered from cell-soluble fraction, but the effect was much more relevant when DNA-bound Pt was analyzed in the presence of cilastatin; DNA-bound $\mathrm{Pt}$ was reduced by $55 \%$ in adherent cells and by $44 \%$ in nonadherent cells.

Speciation studies were performed by SEC/ICP/MS on RPTECs. As Fig. 6C shows, there is no change in the profile of Pt-containing proteins irrespective of whether cells are treated with cilastatin. Pt-bound proteins were observed within the whole separation range $(3-70 \mathrm{kDa})$, and the most intense peaks corresponded to species around 70 and $7 \mathrm{kDa}$. Moreover, no significant peaks were observed for intact cisplatin or the intracellular monoaquo complex, which elute at 47.3 and $30.6 \mathrm{~min}$, respectively, indicating that all $\mathrm{Pt}$ is bound to biomolecules (Fig. 6C).

Cell Type Specificity of Cilastatin Protection: The Case of HeLa Cells. To evaluate the potential loss of the tumoricidal effect of cisplatin caused by the presence of cilastatin, we applied cisplatin to a tumor-derived cell line. When 
A

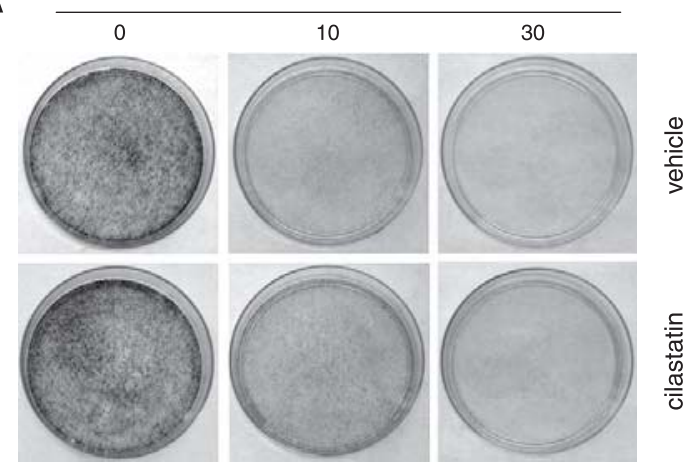

B

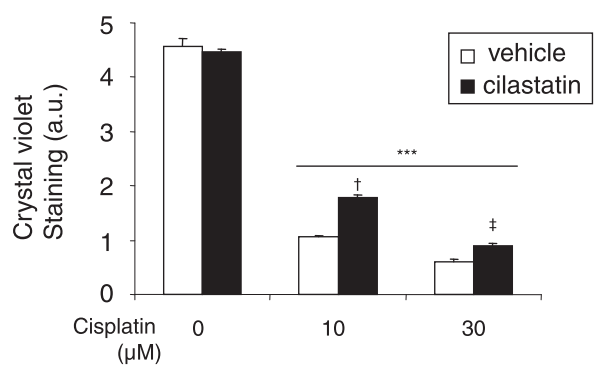

Fig. 5. Cilastatin preserves long-term recovery of cisplatin-treated RPTECs. A, RPTECs plated on six-well plates were incubated with 10 and $30 \mu \mathrm{M}$ cisplatin in the presence or absence of $200 \mu \mathrm{g} / \mathrm{ml}$ cilastatin for $24 \mathrm{~h}$. Cells were then trypsinized, washed, and seeded in Petri dishes in the presence of complete medium with $10 \%$ fetal bovine serum, but without cisplatin or cilastatin, to allow for recovery. The number of CFUs was determined by staining with crystal violet after 7 days. Cilastatin increased the number of long-term surviving cell colonies. The photographs represent three different experiments. $B$, quantification of crystal violet staining. Mean \pm S.E.M. of three experiments. ANOVA model, $P<0.0001$. ***, $P<0.0001$ versus control; $\ddagger, P<0.05 ; \dagger, P<0.0001$ versus same data without cilastatin.

HeLa cells were exposed to increasing concentrations of cisplatin for 24 and $48 \mathrm{~h}$, a dose- and time-dependent cell death was observed. Cilastatin did not have any effect against the cisplatin-induced loss of cell viability (Fig. 7A). We measured DNA-bound Pt both in adherent and nonadherent HeLa cells after 24-h exposure to $30 \mu \mathrm{M}$ cisplatin. Pt concentration was double in nonadherent cells. As expected, cilastatin coincubation did not modify cisplatin binding to DNA (Fig. 7B). To confirm the absence of DHP-I in HeLa cells, we measured the specific DHP-I activity on Gly-Phe dipeptides and its sensitivity to cilastatin inhibition. Figure 7C shows the activity of cilastatin-sensitive DHP-I activity in HeLa cells compared with RPTECs.

Effects of Cisplatin and Cilastatin in Apoptotic Gene Expression in RPTECs. The reduction in DNA-bound Pt induced by cilastatin may play a role in the observed nephroprotection. However, it did not explain why only apoptoticlinked but not necrotic-linked processes were affected by cilastatin. In an attempt to establish whether cilastatin interference with cisplatin death induction could be exclusively explained in terms of reduction in cell cisplatin availability, we decided to explore the gene expression of $\mathrm{TNF} \alpha, \mathrm{Fas}$, and Fas-L as mediators of apoptosis. Cisplatin increased TNF $\alpha$ and Fas mRNA in RPTECs at $24 \mathrm{~h}$, but in contrast it did not modify the level of Fas-L (real-time PCR; Fig. 8). Cilastatin had no effect on the expression of any of the studied genes (Fig. 8), suggesting that transcriptional changes were probably not relevant in cilastatin protection.

Effect of Cisplatin and Cilastatin in Fas-L Distribution. We finally explored the possibility that cilastatinDHP-I interaction could be related to the post-transcriptional induction of apoptosis by cisplatin. Because caspase 3 and caspase 8 were actively induced by cisplatin, we decided to study whether cilastatin modified other steps upstream in the extrinsic pathway of apoptosis. The expression and cell membrane localization of Fas-L were followed by confocal microscopy in RPTECs treated with 30 $\mu \mathrm{M}$ cisplatin for very short periods. Fas-L was identified as specified under Materials and Methods. In Fig. 9A, top, Fas-L is identified on the cell surface after 30-min incubation, but it disappeared from the membrane after $2 \mathrm{~h}$. In the presence of $200 \mu \mathrm{g} / \mathrm{ml}$ cilastatin, a similar pattern was observed at $30 \mathrm{~min}$. However, after $2 \mathrm{~h}$ of treatment, Fas-L was still attached to the membrane, suggesting an inter-
A

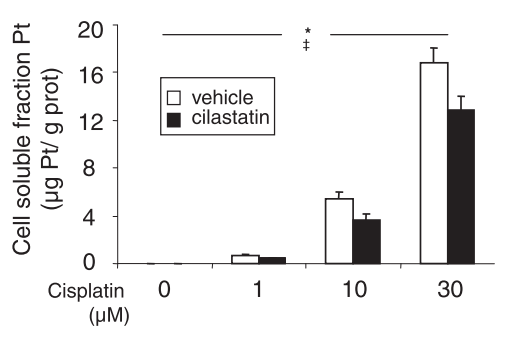

B

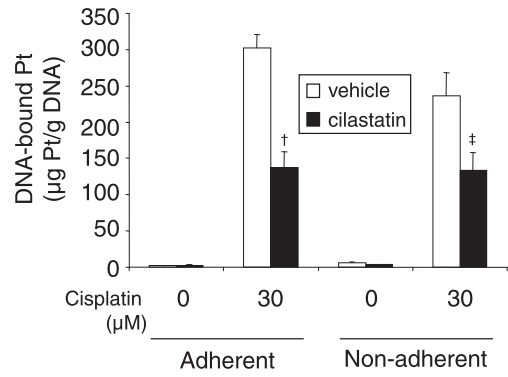

Fig. 6. Effects of cilastatin on cisplatin uptake and speciation analysis in RPTECs. A, platinum was measured in RPTEC-soluble fractions using quadrupole ICP/MS RPTECs were treated with cisplatin in the presence or absence of $200 \mu \mathrm{g} / \mathrm{ml}$ cilastatin for $24 \mathrm{~h}$. Values were expressed as the mean \pm S.E.M. of platinum concentration expressed in micrograms of $\mathrm{Pt}$ per grams of protein ( $n=4$ different experiments). ANOVA model, $P<$ $0.0001 ; *$, cilastatin effect, $P<0.05$; $\ddagger$ dose effect, $P<$ 0.05 . B, DNA-bound platinum was measured under the same conditions using the same methods after DNA extraction from treated RPTECs. Data are presented as the mean \pm S.E.M. of four experiments. ANOVA model, $P<$ 0.0001 . \$, $P<0.05 ; \dagger, P<0.0001$ versus same data without cilastatin. C, SEC/ICP/MS $\left({ }^{195} \mathrm{Pt}\right.$ signal) chromatograms from cytosols of RPTECs treated with $10 \mu \mathrm{M}$ cisplatin with or without $200 \mu \mathrm{g} / \mathrm{ml}$ cilastatin for $24 \mathrm{~h}$. The main chromatographic peaks for the two samples present the same retention times and similar relative intensity. The graph represents three separate experiments. 
A

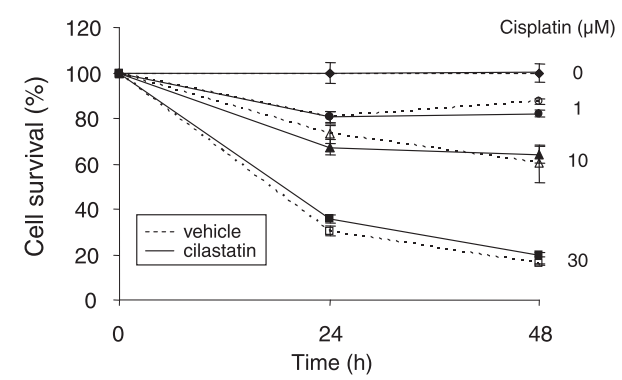

B

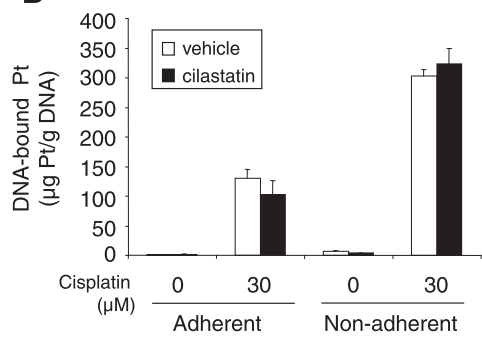

C

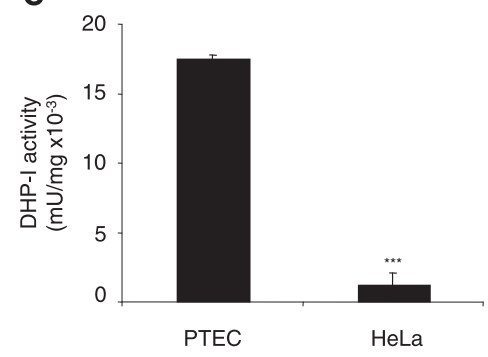

Fig. 7. Effect of cilastatin on the tumoricidal activity of cisplatin on HeLa cells. HeLa cells were treated with cisplatin alone $(1,10$, and $30 \mu \mathrm{M})$ or in combination with 200 $\mu \mathrm{g} / \mathrm{ml}$ cilastatin. A, loss of cell viability was determined at 24 and $48 \mathrm{~h}$ by the ability to reduce MTT (see Materials and Methods). HeLa incubated in the absence of cisplatin and cilastatin was used as $100 \%$. Values are expressed as the mean \pm S.E.M. of four different experiments. ANOVA model, $P<0.0001$; effect of cisplatin, $P<0.0001$; effect of cilastatin, N.S.; effect of time, $P<0.0001$; cilastatin $\times$ cisplatin, N.S.; cilastatin $\times$ time, N.S. B, DNA-bound platinum was measured in HeLa cells isolated DNA using quadrupole ICP/MS. HeLa cells were treated with $30 \mu \mathrm{M}$ cisplatin in the presence or absence of $200 \mu \mathrm{g} / \mathrm{ml}$ cilastatin for $24 \mathrm{~h}$. Values were expressed as the mean \pm S.E.M. of platinum concentration expressed in microgram of $\mathrm{Pt}$ per gram of DNA ( $n=4$ different experiments). C, DHP-Ispecific activity $\left(\mathrm{mU} / \mathrm{mg} \times 10^{-3}\right)$ in cultured RPTECs and HeLa. Activity was determined by the hydrolysis of $1 \mathrm{mM}$ Gly-Phe- $p$-nitroanilide in the presence or absence of 200 $\mu \mathrm{g} / \mathrm{ml}$ cilastatin. $p$-Nitroanilide absorbance was followed at $410 \mathrm{~nm} . * * *, P<0.0001$ versus RPTECs.
A

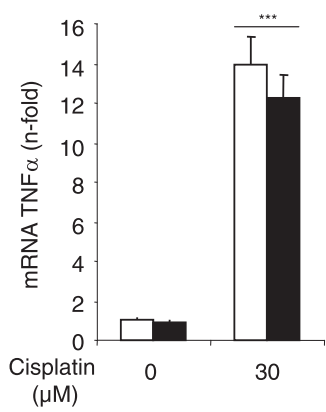

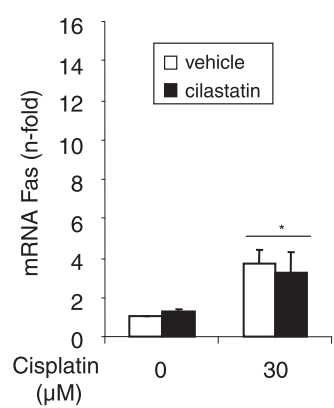

C

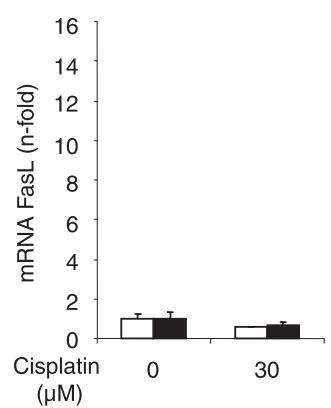

Fig. 8. Effects of cisplatin and cilastatin on mRNA expression of apoptotic genes in RPTECs. RPTECs were cultured in the presence of $30 \mu \mathrm{M}$ cisplatin and cisplatin + cilastatin $(200 \mu \mathrm{g} / \mathrm{ml})$ for $24 \mathrm{~h}$. Expression of TNF $\alpha$ (A), Fas (B), and Fas-L (C) was analyzed by quantitative real-time PCR. Results are mean \pm S.E.M. of four separate experiments. ANOVA models, $P<0.0001 . *, P<0.05 ; * * *, P<$ 0.0001 versus control. ference with ligand site internalization. Quantification of Fas-L staining was performed several times ( 0 and $30 \mathrm{~min}$ and $2 \mathrm{~h}$ ) as shown in Fig. 9B.

\section{Discussion}

Cisplatin accumulation in renal cells causes nephrotoxicity, the main disadvantage of clinical use of cisplatin in oncology (Arany and Safirstein, 2003). The highest concentrations of cisplatin in the kidney are reached in the proximal tubule, where toxicity is both time- and dose-dependent (Ciarimboli et al., 2005; Yao et al., 2007). Proximal tubular cell death is considered the main pathophysiological mechanism underlying cisplatin nephrotoxicity and acute kidney injury and a limiting factor for its clinical use (Pabla and Dong, 2008).

Renal tubular cell death after in vitro exposure to cisplatin has been well documented (Lieberthal et al., 1996; Okuda et al., 2000; Cummings and Schnellmann, 2002; Park et al., 2002). Direct observation of our primary cell cultures under treatment with cisplatin characteristically displayed apoptotic morphological changes that were fully consistent with previous observations (Okuda et al., 2000; Park et al., 2002; Price et al., 2004; Nagothu et al., 2005; Jiang et al., 2007).

In our primary cell culture of RPTECs, cisplatin causes a dose- and time-dependent loss of cells. Although there is some necrosis as confirmed by $\mathrm{LDH}$ release to the medium, most of the cell death seems to be mediated by apoptosis activation. In proximal cells, cisplatin-induced apoptosis may follow both intrinsic and extrinsic pathways. As expected, RPTECs incubated in the presence of cisplatin presented severe mitochondrial damage observed in different ways, including loss of $\Delta \Psi \mathrm{m}$, release of cytochrome $c$, and a diminished capacity to reduce MTT to formazan (Park et al., 2002; Nagothu et al., 2005). In our experimental setup, $\mathrm{TNF} \alpha$ and Fas induction and caspase 8 and 3 activation suggest a relevant involvement of the extrinsic pathway, with persistent caspase activation after $48 \mathrm{~h}$ of exposure. Damaged cells quickly lose the adherent properties.

In this study, we show that cilastatin, a specific inhibitor of tubular brush-border DHP-I, attenuates cisplatininduced nephrotoxicity in vitro, probably in more than one way. At a concentration of $200 \mu \mathrm{g} / \mathrm{ml}$, cilastatin reduced cisplatin-induced caspase activation, cytochrome $c$ release, membrane depolarization, nuclear condensation, DNA fragmentation, and annexin $\mathrm{V}$ exposure and ameliorated viability of surviving cells. Harvesting and reseeding surviving cells allows quantifying the number of CFUs several days after the injury, and consequently the ability to restore a damaged tubule. Cilastatin not only reduced the initial damage to RPTECs but also enabled surviving cells to undergo a better recovery. 


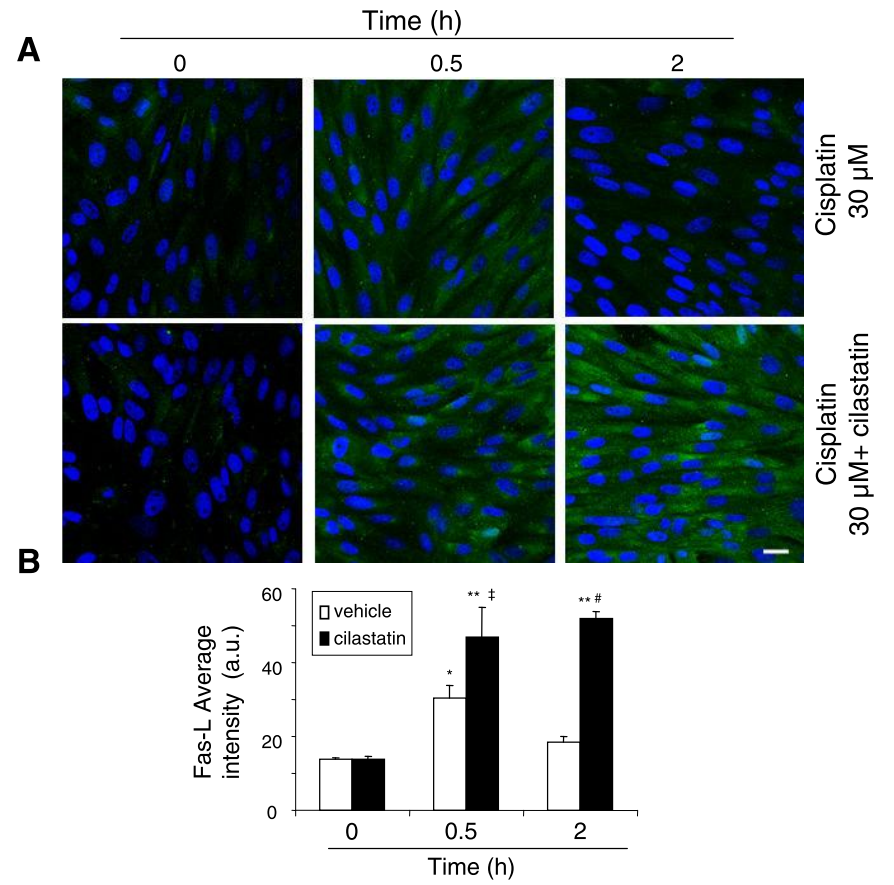

Fig. 9. Effects of cisplatin and cilastatin on immunofluorescence localization of Fas-L. RPTECs were cultured on sterile coverslips and treated for the indicated periods with $30 \mu \mathrm{M}$ cisplatin in the presence or absence of cilastatin $(200 \mu \mathrm{g} / \mathrm{ml})$. A, confocal microscopy images are a representative experiment of three immunofluorescence stainings of Fas-L. $B$, summary of the quantification of Fas-L fluorescence intensity is presented as mean \pm S.E.M. ANOVA model, $P<0.005$; cilastatin effect, $P<$ 0.001 ; time effect, $P<0.005$; cilastatin $\times$ time, $P<0.05$. *, $P<0.05$; **, $P<0.01$ versus control; \#, $P<0.01, \ddagger, P<0.05$ versus same data without cilastatin. Bar, $20 \mu \mathrm{m}$

We chose a concentration close to the expected plasma levels reached in humans treated with imipenem/ cilastatin-200 $\mu \mathrm{g} / \mathrm{ml}$ - even if it was not the most protective concentration. Cilastatin by itself had no significant effects on growth dynamics, cell confluence, or monolayer morphology of RPTECs (Pérez et al., 2004).

Previous results from our group showed that cilastatin also reduced the toxicity of cyclosporine $\mathrm{A}$ and tacrolimus by inhibiting their transcellular transport and consequently their accumulation in the cell (Pérez et al., 2004; Tejedor et al., 2007). Accordingly, we first hypothesized that cilastatin could interfere with cisplatin intracellular accumulation.

Our results show that in the presence of cilastatin there was a modest dose-dependent reduction in cisplatin recovered from cell-soluble fractions. However, cilastatin reduced significantly the amount of DNA-bound cisplatin in monolayer populations and nonadherent cells. Cisplatin is known to permeate proximal tubular cells through apical and basolateral transporters (Miura et al., 1987; Endo et al., 2000), and there is recent evidence that both basolateral OCT1 and OCT2 and copper transporter Ctr1 are involved in cisplatin transport, accumulation, and toxicity (Ciarimboli et al., 2005; Yokoo et al., 2007; Pabla et al., 2009). In both cases, apoptosis and accumulation of cisplatin were decreased but not eliminated in the presence of competitive organic cations or transporter knockdown (Ciarimboli et al., 2005; Yokoo et al., 2007; Pabla et al., 2009). Once inside the cell, the relatively low intracellular chloride concentrations promote the dissociation of the chloride ions from the Pt molecule, thus increasing formation of the reactive, aquated species of cisplatin, which readily interact with intracellular biomolecules (Daley-Yates and McBrien, 1985). Our analyses of intracellular Pt content and the Pt speciation studies on cisplatin-treated RPTECs in the presence or absence of cilastatin showed that cilastatin significantly reduced cisplatin accumulation and DNA binding but did not modify the chromatographic profile corresponding to Pt-containing biomolecules. This indicates that the identity of Pt-biomolecules in the cell is not altered. Therefore, it seems that entry of cisplatin in the cell is partially impaired after administration of cilastatin, with no changes in intracellular cisplatin metabolism.

On the other hand, cilastatin did not prevent cisplatin activation of genes of death, such as $\mathrm{TNF} \alpha$ or Fas, and could not prevent or reduce necrotic cell death. Therefore, reduction in cisplatin intracellular accumulation or in binding DNA was possibly not the only mechanism behind nephroprotection because no pretranscriptional effects were evident.

Caspase 8 and caspase 3 activation suggested a positive role for extrinsic pathway in the observed toxicity of cisplatin on RPTECs (Tsuruya et al., 2003). Cilastatin's first effect should be located in a step between cisplatin-dependent gene induction (not modified by cilastatin) and caspase activation (reduced by cilastatin). Cilastatin affinity for membranebound DHP-I made us focus on a potential interaction at the level of cell death receptor signaling. Cisplatin may induce very rapid Fas clustering in the membrane lipid rafts of cancer cells and may trigger the apoptotic extrinsic cascade, even in the absence of Fas-L (Dimanche-Boitrel et al., 2005). Trimerization of Fas seems to be a rate-limiting step for the process. We have shown that Fas-L binding to the RPTEC membrane is clearly visible $30 \mathrm{~min}$ after cisplatin exposure, and $2 \mathrm{~h}$ later Fas-L binding is no longer visible. This scenario changes when cilastatin is present: Fas-L binds cell membrane after $30 \mathrm{~min}$ of cisplatin exposure, but $2 \mathrm{~h}$ later Fas-L is still binding the membrane surface, with no apparent processing. This interference could be causally related to reductions in caspase 8 and caspase 3 activations, annexin $\mathrm{V}$ exposure, mitochondrial damage, cell detachment, and nucleosome formation observed when cilastatin is coincubated with cisplatin.

Although the exact mechanism behind this interference is not yet clear, it was very relevant to know whether other cell models without cilastatin target on their membranes would be protected by cilastatin against cisplatin toxicity. HeLa cells were our choice because of their tumor origin, the absence of brush border, and the virtual absence of DHP-I activity, this point being directly assessed by us. As expected, cisplatin did cause a sustained and dose-dependent death on HeLa cells, as estimated by the progressive reduction in cell viability (MTT reduction capacity). However, cilastatin did not modify any of these parameters, being not at all protective. DNA-bound cisplatin was not modified by cilastatin in either monolayer or supernatants.

Cilastatin is a molecule specifically designed to inhibit brush border-sorted DHP-I (Parkin et al., 2001; Garner et al., 2007). It is even probable that DHP-I is primarily located in apical cholesterol rafts (Pang et al., 2004) near the Fas site (Dimanche-Boitrel et al., 2005). We do not know whether DHP-I activity is necessary in the mediation of the apoptosis extrinsic signalization or whether it is just an unwanted 
neighbor whose binding to cilastatin may cause a steric interference with the process.

This work supports a new role for cilastatin in reducing cisplatin-induced nephrotoxicity. Identification of additional targets for cilastatin in this protective mechanism, together with currently available pharmacological data on cilastatin, could enable us to develop potent therapeutic strategies for renal function preservation in cancer patients.

\section{Acknowledgments}

We thank Dr. Rafael Samaniego for help with confocal microscopy, Dr. Paqui G. Traves for technical assistance with real-time PCR, and Merck Sharp and Dohme for providing the cilastatin used in the study.

This work is dedicated to the memory of Remedios Fernández (1945-2009).

\section{References}

Arany I and Safirstein RL (2003) Cisplatin nephrotoxicity. Semin Nephrol 23:460464

Binks SP and Dobrota M (1989) Distribution of platinum amongst the subcellular organelles of the rat kidney after oral administration of cisplatin, in Nephrotoxicity. In Vitro to In Vivo Animals to Man (Bach PH and Lock EA eds) pp 331-347, Plenum Press, New York.

Boulikas T and Vougiouka M (2003) Cisplatin and platinum drugs at the molecular level. (Review). Oncol Rep 10:1663-1682.

Ciarimboli G, Ludwig T, Lang D, Pavenstädt H, Koepsell H, Piechota HJ, Haier J, Jaehde U, Zisowsky J, and Schlatter E (2005) Cisplatin nephrotoxicity is critically mediated via the human organic cation transporter 2. Am J Pathol 167:14771484.

Cummings BS and Schnellmann RG (2002) Cisplatin-induced renal cell apoptosis: caspase 3-dependent and -independent pathways. J Pharmacol Exp Ther 302:8-17.

Daley-Yates PT and McBrien DC (1985) A study of the protective effect of chloride salts on cisplatin nephrotoxicity. Biochem Pharmacol 34:2363-2369.

Dimanche-Boitrel MT, Meurette O, Rebillard A, and Lacour S (2005) Role of early plasma membrane events in chemotherapy-induced cell death. Drug Resist Updat 8:5-14.

Endo T, Kimura O, and Sakata M (2000) Carrier-mediated uptake of cisplatin by the OK renal epithelial cell line. Toxicology 146:187-195.

Gallego-Delgado J, Lazaro A, Gomez-Garre D, Osende JI, Gonzalez-Rubio ML Herraiz M, Manzarbeitia F, Fortes J, Fernandez-Cruz A, and Egido J (2006) Long-term organ protection by doxazosin and/or quinapril as antihypertensive therapy. J Nephrol 19:588-598.

Garner AE, Smith DA, and Hooper NM (2007) Sphingomyelin chain length influences the distribution of GPI-anchored proteins in rafts in supported lipid bilayers. Mol Membr Biol 24:233-242.

Go RS and Adjei AA (1999) Review of the comparative pharmacology and clinical activity of cisplatin and carboplatin. J Clin Oncol 17:409-422.

Havlin KA, Kuhn JG, Myers JW, Ozols RF, Mattox DE, Clark GM, and von Hoff DD (1989) High-dose cisplatin for locally advanced or metastatic head and neck cancer. A phase II pilot study. Cancer 63:423-427.

Jiang M, Pabla N, Murphy RF, Yang T, Yin XM, Degenhardt K, White E, and Dong Z (2007) Nutlin-3 protects kidney cells during cisplatin therapy by suppressing Bax/Bak activation. $J$ Biol Chem 282:2636-2645.

Lazaro A, Gallego-Delgado J, Justo P, Esteban V, Osende J, Mezzano S, Ortiz A, and Egido J (2005) Long-term blood pressure control prevents oxidative renal injury. Antioxid Redox Signal 7:1285-1293.

Lee KW, Jeong JY, Lim BJ, Chang YK, Lee SJ, Na KR, Shin YT, and Choi DE (2009)
Sildenafil attenuates renal injury in an experimental model of rat cisplatininduced nephrotoxicity. Toxicology 257:137-143.

Lieberthal W, Triaca V, and Levine J (1996) Mechanisms of death induced by cisplatin in proximal tubular epithelial cells: apoptosis vs. necrosis. Am J Physiol 270:F700-F708

Liverpool Head and Neck Oncology Group (1990) A phase III randomised trial of cisplatinum, methotrextate, cisplatinum + methotrexate and cisplatinum +5 -FU in end stage squamous carcinoma of the head and neck. Liverpool Head and Neck Oncology Group. Br J Cancer 61:311-315.

Miura K, Goldstein RS, Pasino DA, and Hook JB (1987) Cisplatin nephrotoxicity: role of filtration and tubular transport of cisplatin in isolated perfused kidneys. Toxicology 44:147-158.

Nagothu KK, Bhatt R, Kaushal GP, and Portilla D (2005) Fibrate prevents cisplatininduced proximal tubule cell death. Kidney Int 68:2680-2693.

Norrby SR, Alestig K, Björnegård B, Burman LA, Ferber F, Huber JL, Jones KH, Kahan FM, Kahan JS, Kropp $\mathrm{H}$, et al. (1983) Urinary recovery of $N$-formimidoyl thienamycin (MK0787) as affected by coadministration of $N$-formimidoyl thienamycin dehydropeptidase inhibitors. Antimicrob Agents Chemother 23:300-307.

Okuda M, Masaki K, Fukatsu S, Hashimoto Y, and Inui K (2000) Role of apoptosis in cisplatin-induced toxicity in the renal epithelial cell line LLC-PK1. Implication of the functions of apical membranes. Biochem Pharmacol 59:195-201.

Pabla N and Dong Z (2008) Cisplatin nephrotoxicity: mechanisms and renoprotective strategies. Kidney Int 73:994-1007.

Pabla N, Murphy RF, Liu K, and Dong Z (2009) The copper transporter Ctr1 contributes to cisplatin uptake by renal tubular cells during cisplatin nephrotoxicity. Am J Physiol Renal Physiol 296:F505-F511.

Pang S, Urquhart P, and Hooper NM (2004) N-glycans, not the GPI anchor, mediate the apical targeting of a naturally glycosylated, GPI-anchored protein in polarised epithelial cells. J Cell Sci 117:5079-5086.

Park MS, De Leon M, and Devarajan P (2002) Cisplatin induces apoptosis in LLC-PK1 cells via activation of mitochondrial pathways. J Am Soc Nephrol 13: $858-865$.

Parkin ET, Turner AJ, and Hooper NM (2001) Differential effects of glycosphingolipids on the detergent-insolubility of the glycosylphosphatidylinositol-anchored membrane dipeptidase. Biochem $J$ 358:209-216.

Pérez M, Castilla M, Torres AM, Lázaro JA, Sarmiento E, and Tejedor A (2004) Inhibition of brush border dipeptidase with cilastatin reduces toxic accumulation of cyclosporin A in kidney proximal tubule epithelial cells. Nephrol Dial Transplant 19:2445-2455

Price PM, Safirstein RL, and Megyesi J (2004) Protection of renal cells from cisplatin toxicity by cell cycle inhibitors. Am J Physiol Renal Physiol 286:F378-F384.

Servais H, Ortiz A, Devuyst O, Denamur S, Tulkens PM, and Mingeot-Leclercq MP (2008) Renal cell apoptosis induced by nephrotoxic drugs: cellular and molecular mechanisms and potential approaches to modulation. Apoptosis 13:11-32.

Tejedor A, Torres AM, Castilla M, Lazaro JA, de Lucas C, and Caramelo C (2007) Cilastatin protection against cyclosporin A-induced nephrotoxicity: clinical evidence. Curr Med Res Opin 23:505-513.

Tsuruya K, Tokumoto M, Ninomiya T, Hirakawa M, Masutani K, Taniguchi M, Fukuda K, Kanai H, Hirakata H, and Iida M (2003) Antioxidant ameliorates cisplatin-induced renal tubular cell death through inhibition of death receptormediated pathways. Am J Physiol Renal Physiol 285:F208-F218.

Wei Q, Dong G, Franklin J, and Dong Z (2007) The pathological role of Bax in cisplatin nephrotoxicity. Kidney Int 72:53-62.

Wu YJ, Muldoon LL, and Neuwelt EA (2005) The chemoprotective agent $N$-acetylcysteine blocks cisplatin-induced apoptosis through caspase signaling pathway. $J$ Pharmacol Exp Ther 312:424-431.

Yao X, Panichpisal K, Kurtzman N, and Nugent K (2007) Cisplatin nephrotoxicity: a review. Am J Med Sci 334:115-124.

Yokoo S, Yonezawa A, Masuda S, Fukatsu A, Katsura T, and Inui K (2007) Differential contribution of organic cation transporters, OCT2 and MATE1, in platinum agent-induced nephrotoxicity. Biochem Pharmacol 74:477-487.

Address correspondence to: Alberto Tejedor, Renal Physiopathology Laboratory, Department of Nephrology, Hospital General Universitario Gregorio Maranon, C/ Dr. Esquerdo 46, 28007, Madrid, Spain. E-mail: atejedor@senefro.org 